\title{
An analysis of the characteristics of the simultaneous feed-in of photovoltaic and wind power plants based on measured power values
}

\author{
A. Göhlich ${ }^{1}$ and W. Schufft ${ }^{1}$ \\ ${ }^{1}$ Chair of Power Systems and High-Voltage Engineering \\ Department of Electrical Engineering and Information Technology \\ Chemnitz University of Technology \\ Reichenhainer Str. 70, 09107 Chemnitz (Germany) \\ Phone number: +0049 371 531-38344, e-mail: anne.goehlich@etit.tu-chemnitz.de
}

\begin{abstract}
This paper shows the results of the analysis of the measured power values of photovoltaic and wind power plants in the proximity of several electrical substations. The aim is to receive an impression of the frequency, time and duration of very low and very high simultaneous feed-ins of photovoltaic and wind power plants. Therefore, the data of nine electrical substations is analysed. Besides typical statistical values, a comprehensive analysis on the occurrence, extent, distribution, time and duration of the totalized photovoltaic and wind power feed-in is made.

The results show that the occurrence of extreme totalized photovoltaic and wind power feed-in basically depends on the relation $r$ of the installed nominal power of both plant types. For an optimal relation $r$, there are only a few or even almost no very high feed-ins and the number of very small feed-ins can be reduced by balancing the relation $r$ to about 0.5 .
\end{abstract}

\section{Key words}

photovoltaics, wind power, simultaneous feed-in, grid expansion

\section{Introduction}

Due to the continuing expansion of renewable energies in the German medium voltage power grid, distribution system operators among others are confronted with the problem of potential destabilisation of their power supply. Especially the electric power that is being generated by photovoltaic and wind power plants is susceptible to fluctuations which are reflected in the power supply. Locally occurring surplus supply can result in a reversed load flow to the high voltage grids or to a reduction of wind power plants. Conversely an insufficient supply is problematic as well.

For that reason it is of current interest to find out how often states of surplus supply and insufficient supply occur and how long they last. Distribution system operators might find it more economical to endure few of these states in a year than to extend their power grid. Therefore an exact analysis of the feed-in characteristics of photovoltaic and wind power plants and especially their concurrence is necessary.

Previous work has been done by the Reiner Lemoine Institut ([1]) in Berlin, Germany and partially by the Solarenergie-Förderverein Deutschland ([2]). The study [1] uses simulated one hour feed-in values based on global horizontal irridiance and wind speeds for an area of $1^{\circ} \times 1^{\circ}$ (approx. $7,684 \mathrm{~km}^{2}$ ) at $51.5^{\circ} \mathrm{N}, 12.5^{\circ} \mathrm{E}$. The authors of [1] make the point that photovoltaic and wind power complement each other very well concerning critical feed-in overlaps. They define a critical feed-in overlap as the available power that is higher than the nominal power of one of both plant types. [2] refers to the whole of Germany. It states that an ongoing addition of unbuffered photovoltaic plants to the power generation leads only to a marginally increase of photovoltaic power that can be fed in. In times of simultaneous high feed-in of photovoltaic and wind power their totalized power would reach the band of reduction.

The purpose of this paper is to receive an impression of the frequency, time and duration of very low and very high simultaneous feed-ins of photovoltaic and wind power plants. The results of this research will enable more precise statements about potential extension and expansion of medium voltage power grids.

\section{Materials and Methods}

The data base for the analysis descends from an East German distribution system operator that runs the distribution grid in the green area in Fig. 1 which is a part of the Free State of Saxony. The size of this region is about 7,600 square kilometres. It has a rural characteristic and less than 300 inhabitants per square kilometre.

The data base consists of several time series of the feedin power of photovoltaic and wind power plants measured at several meter points within a certain area in the proximity of an electrical substation for the years 2009 to 2011. Its draw area covers an area of about 20 $\mathrm{km}$ around the electrical substation, i.d. about $1,257 \mathrm{~km}^{2}$. 
Theoretically, data for each electrical substation in the distribution system operator's area, which are more than 40, is provided. Practically, the data of nine electrical substations is available by now. The measured values for

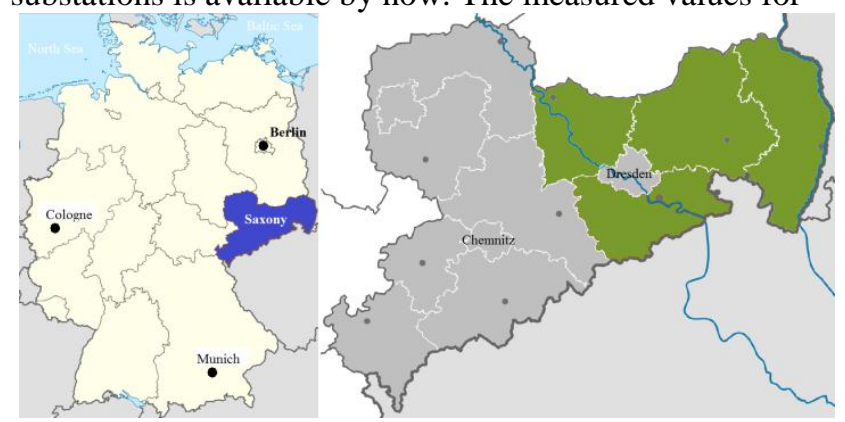

Fig. 1: Map of Germany and Saxony showing the region the regarded distribution system operator is responsible for, [3], [4]

some other will be available. One time series can represent the feed-in power of a single plant as well as of multiple plants measured aggregated at a meter point. The time series of all plants plugged to one electrical substation are not available. Only on four locations up to five time series per photovoltaic or wind power are in place. This implies that the following study cannot be as exact as if it would analyse the single time series of all plants plugged to an electrical substation.

Derived from this data base, one totalized time series representing the feed-in power for all photovoltaic plants and one for all wind power plants for an electrical substation is generated and denoted as $P_{i n P V}$ and $P_{i n W}$. Furthermore, information about the total installed power $\left(P_{\text {instPV }}, P_{\text {instW }}\right)$ as well as the date of implementation for each installed renewable power plant at an electrical substation is provided. Hereafter, each of them is regarded dependently. By speaking of the photovoltaics time series and the wind power time series, the data of the area around one (not all) electrical substation is meant.

Each time series consists of 35,040 values per year representing the average feed-in $\left(\boldsymbol{P}_{\boldsymbol{i n P V}}, \boldsymbol{P}_{\boldsymbol{i n W}}\right)$ for a quarter-hour. To ensure comparability, the time series were scaled to the installed power $\boldsymbol{P}_{\text {inst } P \boldsymbol{V}}$ and $\boldsymbol{P}_{\text {inst } \boldsymbol{W}}$ of the corresponding plant(s). Following, only the scaled feed-ins

$$
\begin{aligned}
P_{S P V} & =\frac{P_{\text {inPV }}}{P_{\text {instPV }}} \cdot 100 \%, \\
P_{S W} & =\frac{P_{\text {inW }}}{P_{\text {instW }}} \cdot 100 \%
\end{aligned}
$$

will be analysed.

After determining the standard statistical key figures as mean, standard deviation and range which will not be dwelt on, several studies concerning the concurrence of photovoltaic and wind power feed-in are made.

\section{Results}

A. Occurrence and extent of totalized photovoltaic and wind power feed-in

For the analysis of the number of occurrences of a certain photovoltaic and wind power feed-in $P_{S P V}$ and $P_{S W}$, a duration curve and a histogram are created first.

Fig. 2 exemplarily shows the duration curve of photovoltaic and wind feed-in $P_{S P V}$ and $P_{S W}$ at a certain electrical substation in 2011. The shape of the green curve essentially depends on the relation

$$
r=\frac{P_{\text {instPV }}}{P_{\text {instPV }}+P_{\text {instW }}}=\frac{P_{\text {instPV }}}{P_{\text {instToT }}}
$$

of the installed photovoltaic and wind power $P_{\text {instPV }}$ and $P_{\text {instw }}$. As a matter of fact, the relation is not constant throughout a year due to newly installed plants. To ensure comparability of the data from different locations and years and to be able to make assertions about the influence of $r$ on the following figures and tables, five different hypothetical $r\left(r_{1}=0, r_{2}=0.2, r_{3}=0.5, r_{4}=\right.$ $\left.0.8, r_{5}=1\right)$ are assumed

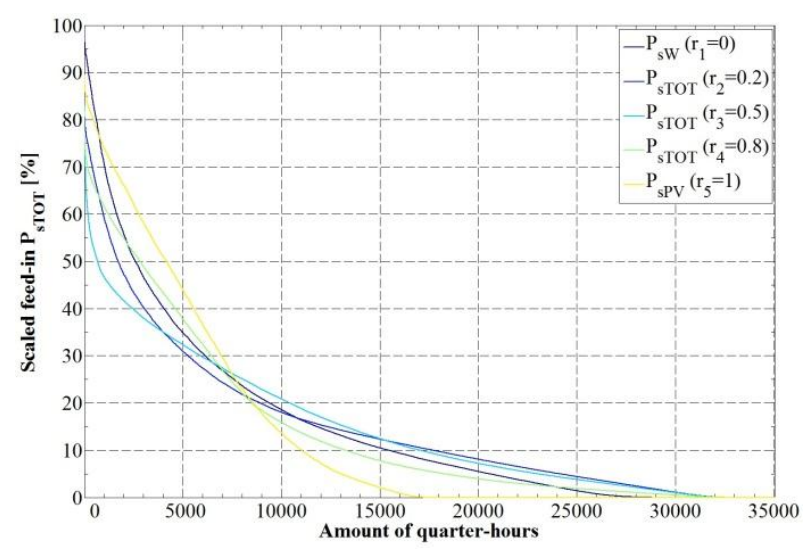

Fig. 2: Duration curves of photovoltaic and wind power feed-in and of their weighted sum in 2011 at location No. 9

The $\mathrm{x}$-axis in Fig. 2 denotes the amount of quarter-hours of one year which is 35,040 . The y-axis denotes the scaled feed-in of photovoltaic and wind power $P_{S P V}$ and $P_{s W}$ and their by $r$ weighted scaled sum

$$
P_{S T O T}=r \cdot P_{S P V}+(1-r) \cdot P_{S W} .
$$

The grey shaped area shows where all possible duration curves are located depending on $r$. The duration curves of photovoltaic and wind power do basically look typical except of the two intersections. They are usual for this locally bounded area. There are three other locations with this characteristic. A faster decreasing of the yellow curve compared to the blue without any intersection is common for most duration curves. The duration curve of the sum $P_{\text {STOT }}$ always has a different look depending on the relation $r$ of the installed power of photovoltaic and wind power $P_{\text {instPV }}$ and $P_{\text {inst } W}$.

It appears that the amount of quarter-hours of the green curves that are not zero is bigger than the amount of the yellow and blue curve. This observation can be 
confirmed by the exact numbers in Table I. It is also of interest how much power is generated by each plant and the by $r$ weighted sum of both. Therefore, the total energy per year $W_{T O T}$ of a combination of photovoltaic and wind plants with totalized weighted installed power

$$
\begin{aligned}
& P_{\text {instToT }}=r \cdot P_{\text {instPV }}+(1-r) \cdot P_{\text {instW }} \\
& =1 \mathrm{MW}
\end{aligned}
$$

is calculated for each $r$. E.g., $r_{1}=0$ leads to pure feed-in by wind power, $r_{2}=0.2$ to $P_{\text {instPV }}=200 \mathrm{~kW}$ and $P_{\text {inst } W}=800 \mathrm{~kW}$ and $r_{5}=1$ to pure feed-in by photovoltaics. The amount of total energy per year of the photovoltaic and wind power plant combined $W_{T O T}$ is between those of the single plants $\left(W_{P V}\right.$ and $\left.W_{W}\right)$ depending on $r$.

Table I. Total energy and feed-in hours in 2011 at location No. 9

\begin{tabular}{|l|c|cc|}
\hline Relation $\boldsymbol{r}$ & & $\begin{array}{c}\text { Total energy } \\
\boldsymbol{W}[\mathbf{M W h}]\end{array}$ & $\begin{array}{c}\text { Feed-in } \\
\text { hours } \\
{[\mathbf{h}]}\end{array}$ \\
\hline $\boldsymbol{r}_{\mathbf{1}}=\mathbf{0}$ & wind & 1336 & 7204 \\
\hline $\boldsymbol{r}_{\mathbf{2}}=\mathbf{0 . 2}$ & & 1312 & \\
$\boldsymbol{r}_{\mathbf{3}}=\mathbf{0 . 5}$ & combination & 1275 & 8124 \\
$\boldsymbol{r}_{\mathbf{4}}=\mathbf{0 . 8}$ & & 1238 & \\
\hline $\boldsymbol{r}_{\mathbf{5}}=\mathbf{1}$ & photovoltaics & 1213 & 4301 \\
\hline
\end{tabular}

Fig. 2 and Table I. imply that the simultaneous feed-ins of photovoltaic and wind power lead to more stable conditions. Furthermore the amount of quarter-hours with a totalized feed-in $P_{\text {STOT }}$ that is larger than zero is bigger than of photovoltaic and wind power feed-in $P_{S P V}$ and $P_{S W}$ individually. The corresponding total energy per year $W_{\text {TOT }}$ ranges between those of photovoltaic and wind power $W_{P V}$ and $W_{W}$ which have a difference of $123 \mathrm{MWh}$ per year. These numbers are valid only for this location.
It is of particular interest for distribution system operators to know how the weighted sum of photovoltaic and wind power feed-in $P_{S T O T}$ is distributed, especially how the distribution behaves at its edges. A histogram is a possibility to show the distribution (Fig. 3). Every colored row shows the histogram for each $\mathrm{r}$. The exact numbers for the columns belonging to $r_{i}, i=1 \ldots 5$ are displayed in Table II. The high number of pure photovoltaic feed-ins $P_{S P V}\left(r_{5}=1\right)$ less or equal zero $(-5 \%-5 \%]$ results from the lack of sunshine during nighttime. The corresponding number for pure wind power feed-ins $P_{s W}\left(r_{1}=0\right)$ is one third smaller and for the weighted sum of photovoltaic and wind power $P_{\text {STOT }}$ it ranges between $50 \%$ and $75 \%$ of the number for $r_{5}=1$. The appearance of the duration curves and histograms for the other nine locations is similar.

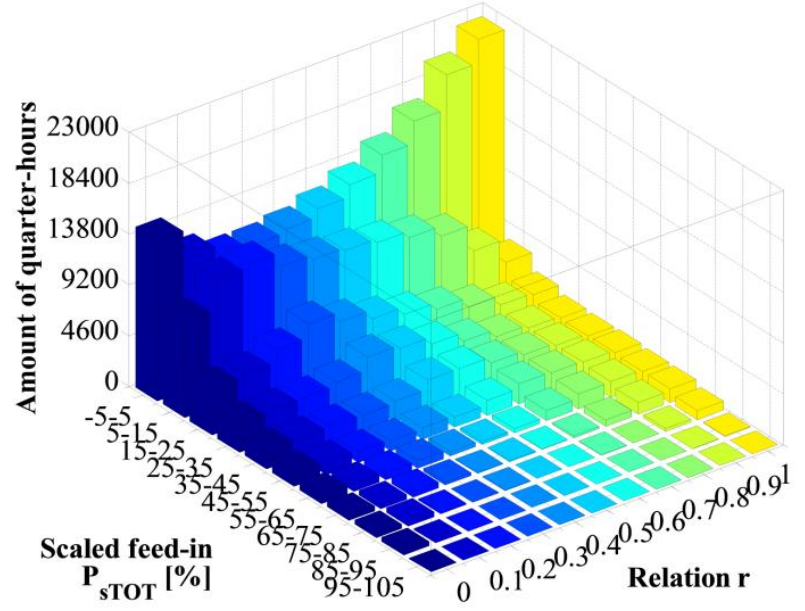

Fig. 3: 3D-histogram of photovoltaic and wind power feed-in for different $\boldsymbol{r}$ in 2011 at location No. 9

Table II. Values of the histogram in Fig. 3 in 2011 at location No. 9

\begin{tabular}{|l|c|ccc|c|}
\hline \multicolumn{1}{|c|}{ Category $C_{i}$} & wind & & combination & \multicolumn{2}{c|}{ photovoltaics } \\
\cline { 2 - 6 } & $\boldsymbol{r}_{\mathbf{1}}=\mathbf{0}$ & $\boldsymbol{r}_{\mathbf{2}}=\mathbf{0 . 2}$ & $\boldsymbol{r}_{\mathbf{3}}=\mathbf{0 . 5}$ & $\boldsymbol{r}_{\mathbf{4}}=\mathbf{0 . 8}$ & $\boldsymbol{r}_{\mathbf{5}}=\mathbf{1}$ \\
\hline$C_{1}=(-5 \% ; 5 \%]$ & 14489 & 10917 & 12030 & 16755 & 22015 \\
\hline$C_{2}=(5 \% ; 15 \%]$ & 8747 & 11809 & 9763 & 7887 & 1982 \\
$C_{3}=(15 \% ; 25 \%]$ & 4202 & 5545 & 5166 & 2998 & 1437 \\
$C_{4}=(25 \% ; 35 \%]$ & 2618 & 2759 & 4059 & 1875 & 1376 \\
$C_{5}=(35 \% ; 45 \%]$ & 1742 & 1714 & 2728 & 1824 & 1425 \\
$C_{6}=(45 \% ; 55 \%]$ & 1162 & 996 & 940 & 1712 & 1268 \\
$C_{7}=(55 \% ; 65 \%]$ & 764 & 626 & 256 & 563 & 1257 \\
$C_{8}=(65 \% ; 75 \%]$ & 502 & 495 & 76 & 36 & 831 \\
$C_{9}=(75 \% ; 85 \%]$ & 408 & 171 & 22 & 0 & 78 \\
$C_{10}=(85 \% ; 95 \%]$ & 359 & 8 & 0 & 0 & 0 \\
\hline$C_{11}=(95 \% ; 105 \%]$ & 47 & 0 & 0 & \\
\hline
\end{tabular}

Fig. 3 and Table II indicate that the number of occurrences of pure photovoltaic and wind feed-ins less or equal zero can be reduced radically by combining photovoltaic and wind power plants in the proximity of an electrical substation.
Another observation drawn from Fig. 3 and Table II is the fact that there are less very high totalized feed-ins $P_{S T O T}$ than photovoltaic and wind power feed-ins $P_{S P V}$ and $P_{S W}$ individually. 


\section{B. Distribution of extreme totalized photovoltaic and wind power feed-ins}

As stated above, extreme feed-ins are of particular interest in this study. $P_{\text {STOT }}$ is defined as an extreme feed-in if

$$
\begin{gathered}
-5 \%<P_{\text {STOT }} \leq 5 \% \\
\text { or } \\
95 \%<P_{\text {STOT }} \leq 105 \% .
\end{gathered}
$$

These boundaries are set with respect to the explanations in the introduction.

The number of extreme feed-ins for different $r$ are displayed in Table III. for all nine locations in 2011. It shows that the number of occurrences of feed-ins $P_{\text {STOT }}$ with $-5 \%<P_{\text {STOT }} \leq 5 \%$ can be reduced for $r_{2}=0.2$ and $r_{3}=0.5$ by combining photovoltaic and wind power plants in the proximity of an electrical substation compared to the amount of photovoltaic and wind power feed-in individually. Furthermore the corresponding number for feed-ins greater than $95 \%$ of the installed power $P_{\text {instToT }}$ can be radically reduced for $r_{3}=0.5$ and $r_{4}=0.8$. Thus it appears that a relation of $r_{3}=0.5$ is best concerning the number of extreme feed-ins. It is possible that a better relation exists but for the five

\begin{tabular}{|c|c|c|c|c|c|c|}
\hline \multirow{2}{*}{$\begin{array}{l}\text { Loc. } \\
\text { No. }\end{array}$} & \multirow{2}{*}{ Extreme situation } & wind & \multicolumn{3}{|c|}{ combination } & \multirow{2}{*}{$\begin{array}{c}\text { photovoltaics } \\
r_{5}=1\end{array}$} \\
\hline & & $r_{1}=0$ & $r_{2}=0.2$ & $r_{3}=0.5$ & $r_{4}=0.8$ & \\
\hline \multirow{2}{*}{1} & $-\mathbf{5} \%<\boldsymbol{P}_{\text {sTOT }} \leq \mathbf{5} \%$ & 11317 & 8464 & 8519 & 11972 & 22851 \\
\hline & $95 \%<P_{\text {STOT }} \leq 105 \%$ & 2369 & 0 & 0 & 0 & 0 \\
\hline \multirow{2}{*}{2} & $-\mathbf{5} \%<\boldsymbol{P}_{\text {STOT }} \leq \mathbf{5} \%$ & 11883 & 8903 & 10040 & 14808 & 22872 \\
\hline & $95 \%<P_{\text {STOT }} \leq 105 \%$ & 380 & 0 & 0 & 0 & 9 \\
\hline \multirow{2}{*}{3} & $-\mathbf{5} \%<\boldsymbol{P}_{\text {STOT }} \leq \mathbf{5} \%$ & 7133 & 4570 & 4942 & 7996 & 14072 \\
\hline & $95 \%<P_{\text {STOT }} \leq 105 \%$ & 380 & 3 & 3 & 4 & 5 \\
\hline \multirow{2}{*}{4} & $-\mathbf{5} \%<\boldsymbol{P}_{\text {STOT }} \leq \mathbf{5} \%$ & 13237 & 10243 & 10746 & 14808 & 22416 \\
\hline & $95 \%<P_{\text {STOT }} \leq 105 \%$ & 0 & 0 & 0 & 0 & 0 \\
\hline \multirow{2}{*}{5} & $-\mathbf{5} \%<\boldsymbol{P}_{\text {sTOT }} \leq \mathbf{5} \%$ & 14023 & 10747 & 12265 & 17846 & 22634 \\
\hline & $95 \%<P_{\text {STOT }} \leq 105 \%$ & 158 & 0 & 0 & 0 & 0 \\
\hline \multirow{2}{*}{6} & $-\mathbf{5} \%<\boldsymbol{P}_{\text {STOT }} \leq \mathbf{5} \%$ & 8676 & 6310 & 6707 & 10275 & 23507 \\
\hline & $95 \%<P_{\text {STOT }} \leq 105 \%$ & 2972 & 0 & 0 & 0 & 0 \\
\hline \multirow{2}{*}{7} & $-\mathbf{5} \%<\boldsymbol{P}_{\text {STOT }} \leq \mathbf{5} \%$ & 12471 & 8962 & 10175 & 15191 & 21882 \\
\hline & $95 \%<P_{\text {STOT }} \leq 105 \%$ & 760 & 0 & 0 & 0 & 0 \\
\hline \multirow{2}{*}{8} & $-\mathbf{5} \%<\boldsymbol{P}_{\text {sTOT }} \leq \mathbf{5} \%$ & 11759 & 8465 & 9577 & 15966 & 22644 \\
\hline & $95 \%<P_{\text {STOT }} \leq 105 \%$ & 196 & 0 & 0 & 0 & 0 \\
\hline \multirow{2}{*}{9} & $-\mathbf{5} \%<\boldsymbol{P}_{\text {sTOT }} \leq \mathbf{5} \%$ & 14489 & 10917 & 12030 & 16755 & 22015 \\
\hline & $95 \%<P_{\text {STOT }} \leq 105 \%$ & 47 & 0 & 0 & 0 & 0 \\
\hline
\end{tabular}
regarded $r, r_{3}=0.5$ is optimal.

Table III. Frequency of extreme feed-ins in 2011

With knowledge about the number of certain feed-in situations, the question arises which type of renewable energy is mostly responsible for extreme feed-ins. It can be answered by a scatter plot (Fig. 4). Every circle in the figure corresponds to a special photovoltaic-wind powerconfiguration that occurred in the observed year. The resulting amount of power of each circle cannot be identified which is why lines for each power level were added. The location of the circles does not change for different relations $r$, however the location of the level lines. Thus, for different relations $r$ different circles in the scatter plot can be detected as extreme feed-ins and therefore different contributions of photovoltaic and wind power to the particular extreme situation. The number of circles between two level lines corresponds to the number in Table II. E.g. the number of circles in Fig. 4a) between the $85 \%$ and the $95 \%$ level line is 8 which is also displayed in Table II.

\section{Time and duration of extreme totalized photovoltaic and wind power feed-in}

As important as the contribution of photovoltaic and wind power to extreme totalized photovoltaic and wind power feed-ins, the time and duration of their occurrence is of interest. The analysis of the time is divided in occurrences within a year and a day. The duration of an extreme feed-in is given in hours. The analysis shows a seasonal dependence of occurrence of very low feed-ins which increases as the relation $r$ increases. This means that for a small relation $r$, which is equivalent to a small installed nominal power of photovoltaic plants $P_{\text {instPV }}$, the number of very low feed-ins is either almost uniformly distributed or fluctuates within a year. Vice versa, a big relation $r$ increases seasonal dependencies caused by the bigger influence of photovoltaic plants with the effect that there are more very low feed-ins in winter than in summer. The same applies to seasonal 
dependencies of very high feed-ins with the difference of cumulative occurrences in summer for a big relation $r$. Corresponding assertions can be made about the dependence on the daytime.

The duration of very low feed-ins $\left(P_{\text {STOT }} \in C_{1}\right)$ is mostly between 1 and 48 quarter-hours, i.e. between one $1 / 4 \mathrm{~h}$ and 12 hours. The duration of very high feed-ins $\left(P_{\text {STOT }} \in C_{11}\right)$ - if there are any - is without exception one quarter- hour and therefore independent of the relation $r$.
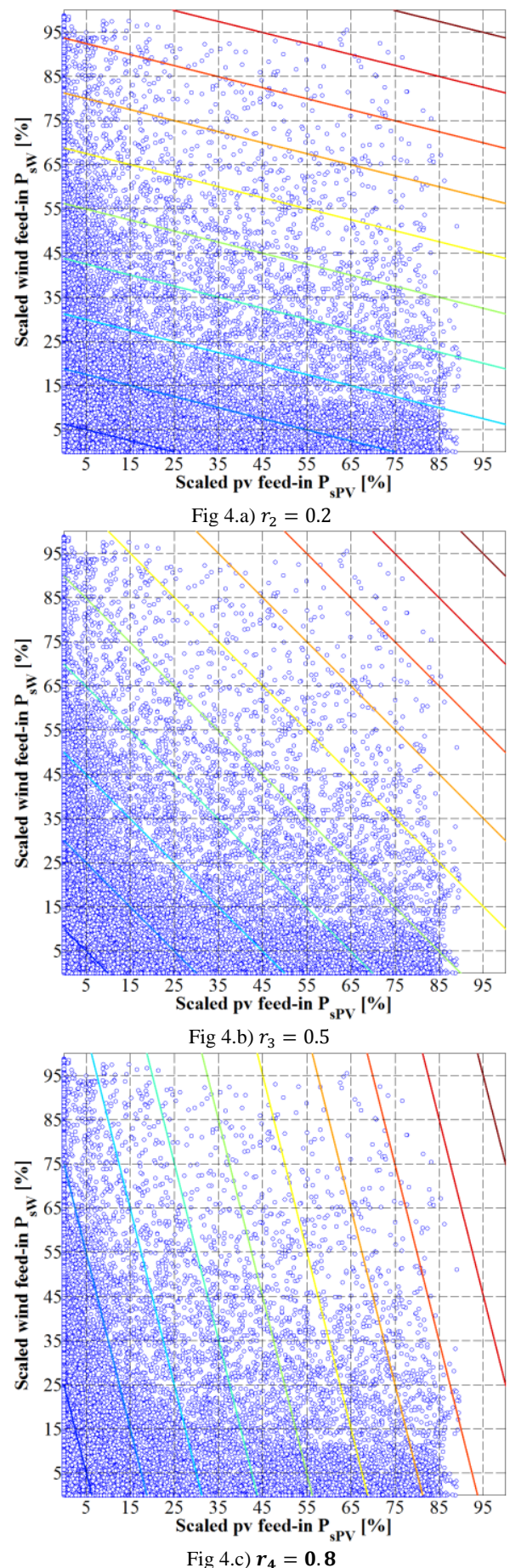

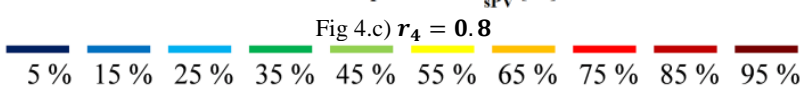

Fig. 4: Scatter plot of photovoltaic and wind power feed-in and level lines of their weighted sum for $r_{2}=0.2, r_{3}=0.5, r_{4}=0.8$ in 2011 at location No. 9

\section{Conclusions}

The analysis shows that the occurrence of extreme totalized photovoltaic and wind power feed-in $P_{\text {STOT }}$ basically depends on the relation $r$ of the installed nominal power of both plant types, $P_{\text {instPV }}$ and $P_{\text {instw }}$. An optimal relation $r$ referring to a small number of extreme totalized feed-ins is a relation $r$ of about 0.5 . The optimal relation $r$ might be different for every location and has to be regarded as a theoretical value but the fact will not change that a mixture of about fifty-fifty of photovoltaic and wind power plants in the proximity of an electrical substation is advantageous. The expression optimal relation $r$ is of theoretical nature since the addition of photovoltaic and wind power capacity is usually limited by geographical, economical and political conditions. For all practical purposes the optimal relation $r$ has to be adapted to reality.

Referring to [1] the results confirm that photovoltaic and wind power plants complement each other very well concerning critical feed-in overlaps or, as defined in this paper, extreme feed-ins. A difference is that the regarded area is much smaller and the data is more high-resolution than in [1] which might complicate the whole situation of the occurrence of extreme feed-ins. However, this cannot be confirmed as the amount of extreme especially very high feed-ins is not big for an optimal relation $r$.

The results of this study show that the number of extreme feed-ins in the proximity of an electrical substation can be partially radically reduced by taking care of a balanced relation of photovoltaic and wind power plants in the respective area. The time of extreme feed-ins as well depends on the relation $r$ with an increased dependency for increasing $r$. The duration of extreme feed-ins is without exception one quarter-hour.

The conclusions drawn from this paper are mostly of economical nature. It might be more economical for a distribution system operator to endure few of these states with the possible consequences of reduction of especially wind power plants than to extend single cords or overhead lines. For being able to make assertions about this problem, the load in the commuting area of an electrical substation has to be analysed and related to the feed-in at the same time.

Another task is to emulate the feed-in by a stochastic process in order to find out more about possible dependencies between the photovoltaic and wind power feed-in.

\section{References}

[1] A.-K. Gerlach, Ch. Breyer, "PV und Windkraft: Sich hervorragend ergänzende Energietechnologien am Beispiel Mitteldeutschlands", 27. Symposium Photovoltaische Solarenergie, Bad Staffelstein (2012).

[2] W. von Fabek, "Zusammenwirken von Photovoltaik, Windkraft und Energiespeichern", Ein Vorschlag des Solarenergie-Fördervereins Deutschland (2012) 